\title{
Avaliação da carga suspensa total (CST) e de metais na bacia do córrego Pinhalzinho II no município de Umuarama - PR
}

\begin{abstract}
RESUMO: Visando avaliar a influência antrópica na qualidade hídrica da bacia do córrego Pinhalzinho II, em Umuarama no noroeste Paranaense, buscou-se nesse trabalho, determinar a carga suspensa total (CST) e as concentrações dos metais: $\mathrm{Cu}, \mathrm{Mn}, \mathrm{Fe}, \mathrm{Ni}, \mathrm{Cr}, \mathrm{Pb}, \mathrm{Cd}$, As, Se e $\mathrm{Zn}$ nas águas. Para isso foram selecionados quatro pontos de amostragem na bacia. As amostras de água foram coletadas sazonalmente com o intuito de analisar todas as estações do ano, em decorrência das diferentes condições de clima. Os resultados parciais evidenciam teores elevados de $\mathrm{Fe}$ e $\mathrm{Mn}$, que se encontram acima dos valores permitidos pela resolução CONAMA n³57/2005. A carga suspensa total é composta principalmente por matéria orgânica.
\end{abstract}

\section{Evaluation of total suspended load (CST) and metals in the basin of Pinhalzinho II stream in Umuarama - PR}

ABSTRACT: To evaluate the anthropogenic influence on water quality in the basin of the Pinhalzinho II stream in the northwest Umuarama Paranaense, we sought in this work, to determine the total suspended load (CST) and the concentrations of metals: $\mathrm{Cu}, \mathrm{Mn}, \mathrm{Fe}, \mathrm{Ni}, \mathrm{Cr}, \mathrm{Pb}, \mathrm{Cd}$, Se and $\mathrm{Zn}$ in the waters. For this purpose we selected four sampling points in the basin. Water samples were collected seasonally in order to analyze all the seasons, due to different weather conditions. Partial results show higher Fe and Mn, which lie above the values allowed by the CONAMA Resolution 357/2005. The total suspended load is mainly composed of organic matter.
Maria Estela Casale Dalla Villa*

* Mestre em Geografia pela UEM

Palavras-chave:

Degradação ambiental; Usos do solo; Metais; Carga suspensa total.

Key-words: Environment degradation; Soil use; Metals; Total suspended load. 


\section{Introdução}

Com o avanço da ocupação humana sobre os mais diversos ecossistemas, várias têm sido as formas de impactos sobre o equilíbrio ecológico, principalmente na qualidade hídrica de uma bacia.

A qualidade da água está sendo afetada pela ocupação e manejo inadequados do solo, resíduos industriais, uso de agrotóxicos e fertilizantes, desmatamento e falta de tratamento de esgoto, provocando entre outros danos, a introdução de metais e o aumento da carga suspensa total hidrotransportada.

A presença de metais nas águas tem proporcionado predizer ou identificar as fontes de poluição e o grau de extensão desses poluentes, uma vez, que representam uma ameaça ao equilíbrio dos ecossistemas naturais, além de comprometer a saúde humana.

$O$ aumento da carga suspensa também pode comprometer a qualidade da água.

A carga suspensa é o produto final da atuação de uma série de processos que se iniciam com a precipitação que cai sobre a bacia e ao longo de seu percurso pelas vertentes interagindo com um conjunto de variáveis, como: cobertura vegetal, tipo de solo e de rocha, tipo de uso e de ocupação da bacia pelo homem. Pode servir também como meio de adsorção, transporte, bem como alterar a biodisponibilidade do metal.

A área de estudo é a bacia do córrego Pinhalzinho II, a qual abrange como afluentes o córrego Cedro e o Ribeirão Esperança. Pertence ao município de Umuarama, que a exemplo de outros municípios do noroeste do Paraná, vem desde sua criação experimentando um rápido e desorganizado crescimento, transformando a cobertura vegetal ou em áreas urbanas, ou em áreas de uso agrícola, que acabam gerando diversos tipos de resíduos e que inevitavelmente acabam atingindo corpos d'água.

Frente a estas constatações, esse trabalho tem como principal objetivo avaliar a carga suspensa total e quantificar a presença dos metais: Cobre $(\mathrm{Cu})$, Manganês $(\mathrm{Mn})$, Ferro $(\mathrm{Fe})$, Níquel (Ni), Cromo ( $\mathrm{Cr}$ ), Chumbo (Pb), Cádmio (Cd), Arsênio (As), Selênio (Se), Zinco (Zn) nas águas.

Esses elementos foram escolhidos por estarem, de acordo com Förstner et al. (1990) entre os mais estudados do ponto de vista toxicológico. Muitos desses metais são naturalmente incorporados à água durante o próprio ciclo hidrológico. Porém, suas concentrações podem ser drasticamente aumentadas com uso em larga escala de produtos químicos na agricultura e a disposição inadequada de resíduos industriais e urbanos.

Para atingir o objetivo proposto foram determinados quatro pontos de amostragem. As campanhas foram sazonais.

Essa pesquisa é fundamental para futuros estudos nesse ambiente, pois permite uma comparação com futuras alterações na concentração da carga suspensa e de metais, portanto, estabelece o estado de degradação ou preservação que ela se encontra.

Geografia Ensino \& Pesquisa, v. 15, n.2, p. 63-74, maio.lago. 2011

Avaliação da carga suspensa total (CST) e de metais na bacia do córrego Pinhalzinho II no município de Umuarama - PR

\section{Área de estudo}

A área de estudo é a bacia do córrego Pinhalzinho II, localizada na região noroeste do Paraná (Fig.1). Essa bacia se desenvolve nos municípios de Umuarama num pequeno setor do município de Cruzeiro do Oeste. 
Compreende uma área de aproximadamente $182,6 \mathrm{~km} 2$, centrado pelas coordenadas geográficas $23^{\circ} 47^{\prime} 55^{\prime \prime} \mathrm{S}$ de latitude e $53^{\circ} 18^{\prime} 48^{\prime \prime}$ W de longitude e altitude em torno de $182 \mathrm{~m}$. A extensão do canal do córrego Pinhalzinho II, é entorno de $27,8 \mathrm{Km}$, sendo classificado como canal de $5^{\mathrm{a}}$ ordem, e regime hídrico perene, ou seja, constante no decorrer do ano. (IPARDES, 2004).

Pertence ao Terceiro Planalto Paranaense, se destaca pela Formação Caiuá. A vegetação nativa do noroeste do estado é caracterizada pela Floresta Estacional Semidecidual (FES) (MAACK 2002).

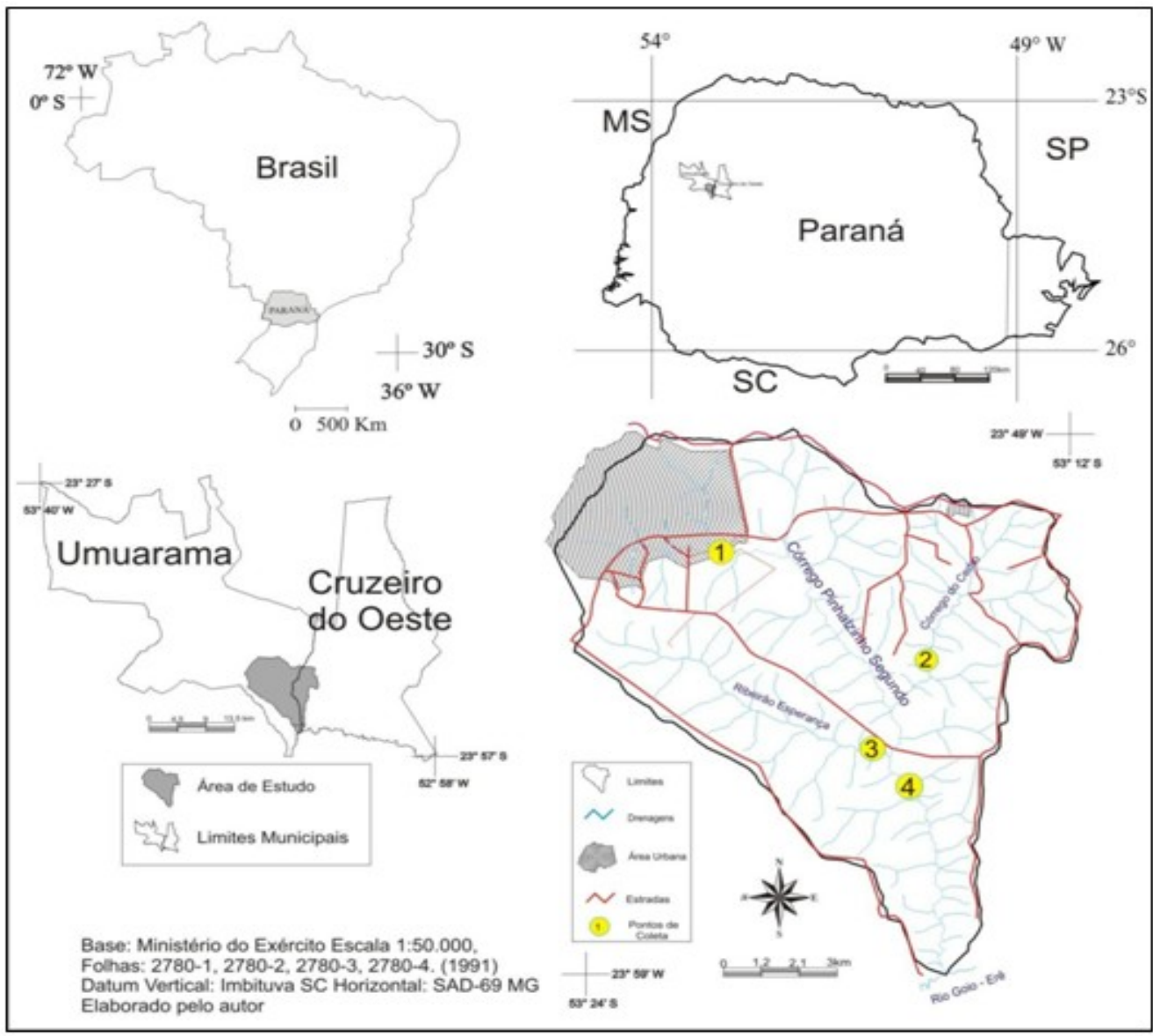

Figura 1- Localização da bacia do córrego Pinhalzinho II

\section{Origem dos metais e a importância da análise química da água}

Metais em corpos hídricos provêm de diversas fontes, podendo ser dividida em natural e de origem antrópica. Normalmente apresentam-se em concentrações muito pequenas, associados a outros elementos químicos, formando minerais em rochas. Quando lançados no meio ambiente como resíduos industriais podem ser absorvidos pelos tecidos animais e vegetais contaminando os ecossistemas terrestres e aquáticos.

Portanto, com a industrialização, a concentração dos metais tem aumentado de maneira surpreendente, fazendo com que os metais, antes inofensivos ao homem, se tornassem uma das mais graves e temidas formas de poluição ambiental que se tem conhecido.

Geografia Ensino \& Pesquisa, v. 15, n.2, p. 63-74 maio./ago. 2011

Villa, M. E. C. D.

As principais fontes de metais no sistema aquático são provenientes do escoamento dos solos e das emissões industriais. Portanto a origem dos metais encontrados no ambiente 
aquático depende das características geológicas e ecológicas das bacias de drenagem e principalmente do tipo de atividade humana presente.

Nos ecossistemas aquáticos, o transporte dos metais é realizado principalmente sob forma dissolvida ou ligada ao material particulado em suspensão. Dependendo das condições ambientais, o metal pode variar a sua densidade e diversidade.

Andrade (2003) destaca que a maioria desses elementos exerce um importante papel biológico na construção de estruturas orgânicas e gerência dos fluxos de nutrientes e energia nos organismos e por isso são classificados como essenciais e não-essenciais. 0 mesmo autor destaca que vários metais como o boro, o cobre, o manganês e o zinco, são tidos como essenciais para as plantas e só tornam-se tóxicos, quando acima de certos níveis de concentração.

Geralmente os metais são elementos reativos e persistentes, que entrando no sistema hídrico podem reagir com o material suspenso, com a matéria orgânica dissolvida e outros, onde acabam sendo depositados nos sedimentos. De acordo com Baird (2002) o pH também influência na toxidade de uma dada concentração de metal pesado presente em um curso d'água natural.

Os metais são perigosos contaminantes tanto em escala local como global, pois podem causar efeitos crônicos tanto as comunidades aquáticas como a saúde humana, por isso é de fundamental importância o estudo de metais na coluna d'água.

Nessa pesquisa foram estudados os seguintes metais:

0 arsênio (As) é usado na fabricação de munição, ligas e placas de chumbo de baterias elétricas, herbicidas e inseticidas. As fontes de arsênio para o ambiente provêm do uso continuado de seus compostos como pesticidas, herbicidas de sua emissão durante a mineração e fundição de ouro, chumbo, cobre e níquel, da produção de ferro e aço e da combustão de carvão. A ingestão de água constitui como principal fonte de arsênio para a maioria das pessoas, podendo causar câncer de pulmão, câncer de pele e de fígado (BAIRD, 2002).

$\mathrm{O}$ níquel (Ni) é utilizado em galvanoplastia e em atividades metalúrgicas com varias finalidades, principalmente para dar maior resistência ao aço contra a corosão. Não existem muitas referências bibliográficas quanto à toxicidade do níquel. Todavia intoxicações mesmo leves por níquel podem causar sintomas de apatia, diarréia, febre, insônia e náuseas, podendo desenvolver câncer principalmente no pulmão (CETESB, 2009).

$\mathrm{O}$ cromo $(\mathrm{Cr})$ encontra-se naturalmente em matrizes não poluidoras, torna-se poluidor a partir da ação humana. Podendo incidir como contaminante de águas sujeitas a lançamentos de efluentes de curtumes e de circulação de águas de refrigeração, onde é utilizado para o controle da corrosão. $O$ cromo é largamente utilizado em aplicações industriais e domésticas, como na produção de alumínio, sendo muito comum nos revestimentos de peças, aço inoxidável, tintas, pigmentos, explosivos, papel e soldagens. Produz efeitos corrosivos no aparelho digestivo e nefrite (CETESB, 2009).

As fontes de cobre $(\mathrm{Cu})$ para o meio ambiente incluem corrosão de tubulações de latão por águas ácidas, efluentes de estações de tratamento de esgotos, fungicidas e precipitação atmosférica de fontes industriais. É prejudicial à saúde produzindo intoxicação com lesões no fígado e ainda confere sabor às águas. Em pequenas quantidades é até benéfico ao organismo humano, catalisando a assimilação do ferro e seu aproveitamento na síntese da hemoglobina do sangue, facilitando a cura de anemias (CETESB, 2009).

O chumbo $(\mathrm{Pb})$ está "naturalmente" presente nas rochas, solo e água, porém em concentrações não poluidoras. A contaminação por chumbo provém da ação antrópica, 
geralmente da poluição ocasionada pelos gases industriais e depósitos de indústria metalúrgica, encanamentos, soldas, plásticos, tintas, munições, pigmentos, clínicas dentarias (KLASSEN, 1999).

O chumbo $(\mathrm{Pb})$ pode ser incorporado ao cristal na fabricação de copos, jarras e outros utensílios, podendo dessa forma ser incorporado aos alimentos. Compostos de chumbo são absorvidos por via respiratória e cutânea ou absorvidos através da pele. Constitui veneno cumulativo atingindo o sistema nervoso, a medula óssea e os rins (BAIRD, 2002).

O cádmio ( $\mathrm{Cd}$ ) possui alta toxicidade com dose letal de aproximadamente um grama, sendo razoavelmente volátil quando aquecido. As formas de contaminação por cádmio podem ser a partir de resíduos da fabricação de cimento, da queima de combustíveis fósseis e lixo urbano e de sedimentos de esgotos. É usado como eletrodos de baterias recarregáveis (níquelcádmio) usada em calculadoras e aparelhos similares. Na agricultura, uma fonte direta de contaminação pelo cádmio é a utilização de fertilizantes fosfatados, o lodo de esgoto contaminado com o cádmio emitido pelas indústrias aumenta o nível desse elemento no solo e consequentemente nas plantas que crescem sobre ele contaminando a natureza, causando problemas gastrointestinais e respiratórios (BAIRD, 2002).

O selênio $(\mathrm{Se})$ geralmente está presente nas águas devido ás descargas de efluentes industriais. É altamente tóxico podendo causar: artrite, cansaço, halitose, irritabilidade, disfunção renal, desconforto muscular e pele amarelada (CETESB, 2009).

Apesar de 0 zinco $(Z n)$ ser um micronutriente essencial à biota, em determinadas condições ele pode ser considerado como indicador da ação antrópica, ou seja, de poluição proveniente de indústrias (CETESB, 2009). Pode contaminar o meio aquático a partir de rejeitos da atividade de mineração e de efluentes domésticos não-tratados (MARTIN et al., 1976). De acordo com Lewis (1996) o índice de toxicidade do zinco (Zn) é baixo, mas em concentrações altas é prejudicial à saúde podendo se acumular nos tecidos do organismo.

O manganês $(\mathrm{Mn})$ está entre os metais mais abundantes na natureza. $\mathrm{O}$ trato respiratório é a principal via de introdução e absorção desse metal. O seu comportamento nas águas é muito semelhante ao do ferro $(\mathrm{Fe})$, porém sua ocorrência é mais rara. $\mathrm{O}$ manganês $(\mathrm{Mn})$ desenvolve coloração negra na água. É muito usado na indústria do aço, na fabricação de ligas metálicas, baterias e na indústria química de tintas, vernizes, fogos de artifícios, fertilizantes, fungicidas e rações entre outros (CETESB, 2009). Seu excesso no organismo humano pode causar: anorexia, alucinações, dificuldade de memorização, insônia e dores musculares.

$\mathrm{O}$ ferro $(\mathrm{Fe})$ não se constitui em elemento altamente tóxico, mas traz diversos problemas para 0 abastecimento público de água, pois atribui cor e sabor à água podendo provocar manchas em roupas e utensílios sanitários. $O$ ferro $(\mathrm{Fe})$ pode formar depósitos em canalizações e de ferro-bactérias, provocando a contaminação biológica da água na própria rede de distribuição. $O$ excesso de ferro $(\mathrm{Fe})$ no organismo pode provocar anorexia, tontura, fadiga e dores de cabeça (CETESB, 2009).

\section{Metodologia}

As amostras foram coletadas num período de 1 ano (2008 a 2009), durante as estações (primavera, verão, outono e inverno), ou seja, as coletas foram sazonais permitindo verificar as alterações nas quantidades de metais presentes na água, bem como as variações na carga

Geografia Ensino \& Pesquisa, v. 15, n.2, p. 63-74, maio./ago. 2011

Villa, M. E. C. D. 
suspensa total. Os fracos foram introduzidos no corpo d'água a uma profundidade de aproximadamente $20 \mathrm{~cm}$. Todas as coletas foram realizadas no período da manhã.

Foram selecionados quatro pontos de coleta: o primeiro ponto localizado na cabeceira de drenagem do córrego Pinhalzinho II (sob influência da área urbana), o segundo ponto no córrego Cedro (localizado na área rural, caracterizado principalmente por pastagem), o terceiro ponto no córrego Esperança (localizado na área rural, caracterizado por pastagem e cultivo de cana-deaçúcar) e o quarto ponto próximo da foz do córrego Pinhalzinho II, os quais foram determinados para mostrar as variações da quantidade total de metais presentes sob diferentes usos da terra.

\section{Procedimentos de coleta e análise de Metais}

A metodologia utilizada para análise dos metais em água seguiu as etapas proposta por Keith (1996).

As amostras de água foram coletadas utilizando garrafas de polietileno com capacidade de 2 litros, acidificadas com $5 \mathrm{ml}$ ácido nítrico (PA-65\%) no momento da coleta e mantidas sob refrigeração. Posteriormente, em laboratório as amostras foram colocadas em becker de $500 \mathrm{ml}$, sendo acrescidos mais $5 \mathrm{ml}$ de ácido nítrico e mantidas em chapa aquecedora $\left(100{ }^{\circ} \mathrm{C}\right)$, até concentrarem-se em $25 \mathrm{ml}$, através da evaporação. Em seguida as amostras foram colocadas em balão volumétrico e diluídas com água deionizada até atingir $50 \mathrm{ml}$, para leitura dos metais. $\mathrm{A}$ leitura dessas amostras foi efetuada utilizando-se a técnica de Espectrometria de Absorção Atômica - chama (SpectrAA - 10 Plus. Varian. 1994). Todas as análises foram realizadas em triplicata e a concentração de cada elemento determinada em mg.L-1.

Os procedimentos adotados estão de acordo com o Standard Methods for the Examination of Water and Wastewater (APHA, AWWA, WPCF, 1989).

As concentrações dos metais da água foram comparadas com os limites toleráveis (LT) definidos pela Resolução CONAMA n³57/2005.

\section{Procedimentos para determinação da carga suspensa total (CST)}

A determinação da carga em suspensão foi obtida pelo método descrito por Orfeo (1995). Optou-se pelo método de filtragem utilizando a bomba a vácuo e filtros analíticos AP40 em microfibra de vidro, sem resina, $47 \mathrm{~mm}$ de diâmetro. As análises foram realizadas no laboratório de sedimentologia do Grupo de Estudos Multidisciplinares do Ambiente - GEMA/UEM.

Primeiramente os filtros foram numerados e colocados na mufla por um período de 1 hora a temperatura constante de $480{ }^{\circ} \mathrm{C}$ para eliminação de possíveis interferências. Após os filtros foram colocados no dessecador por 20 minutos, depois pesados em balança analítica de precisão até obter peso constante.

De cada ponto amostral foi filtrada uma alíquota de 1 litro de água superficial. Os filtros

Geografia Ensino \& Pesquisa, v. 15, n.2, p. 63-74, maio./ago. 2011

Avaliação da carga suspensa total (CST) e de metais na bacia do córrego Pinhalzinho II no município de Umuarama - PR foram conectados a um Kitassato acoplado a uma bomba a vácuo. Após a filtragem as amostras foram secas em estufa à temperatura de $105^{\circ} \mathrm{C}$ durante $24 \mathrm{~h}$, em seguida os filtros foram colocados no dessecador por 20 minutos e pesados em balança analítica de precisão até obter peso constante. 
Para determinação do conteúdo mineral e da matéria orgânica em suspensão, os filtros foram colocados na mufla a temperatura de $480^{\circ} \mathrm{C}$ por 4 horas, sendo novamente colocados no dessecador e pesados. A equação para determinação da carga suspensa total e matéria orgânica é explicada no quadro 1.

\begin{tabular}{|c|c|c|}
\hline Carga total em suspensão & Matéria orgânica em suspensão & Sedimento em suspensão \\
\hline Css $=\left(\begin{array}{c}\text { Peso final }- \text { Peso inicial) }) \\
1000 / 0,5\end{array}\right.$ & $\begin{array}{c}\text { MO (Peso final }- \text { Peso pós-queima }) \\
\times 1000 / 0,5\end{array}$ & Ss $=($ Css - MO $)$ \\
\hline
\end{tabular}

Onde: Css (carga total em suspensão); 1000 (para a conversão das unidades g em mg) e 0,5 (corresponde ao volume filtrado). MO (matéria orgânica em suspensão); Ss (sedimento em suspensão).

Quadro 1 - Equação para análise da carga em suspensão

\section{Resultados e discussão}

\section{Carga Suspensa Total (CST)}

Carga Suspensa Total é constituída de pequenas partículas que se encontram suspensas na água, as quais têm uma fração mineral ou inorgânica e outra orgânica.

As concentrações do material em suspensão são bastante variáveis no tempo e no espaço, e dependem da hidrodinâmica, da constituição do substrato de fundo, das margens do meio hídrico e ainda de fatores metereológicos.

De acordo com Coelho (2007), o monitoramento da carga suspensa é muito importante, pois representa a quantidade de sedimentos produzidos na bacia, uma vez que demonstra, de forma indireta, a presença dos processos erosivos. 0 excesso de sólidos é sempre um perigo para a fauna e flora do ecossistema local e representa uma perda de qualidade da água. Além de possuir importante papel na adsorção e transporte de metais, e diversos outros contaminantes ao longo do sistema lótico, contribuindo para que os metais, eventualmente presentes nos sistema hídrico, se tornassem menos biodisponíveis.

De acordo com metodologia de Orfeu (1995) os dados encontrados foram sumarizados em carga suspensa total (CST) e matéria orgânica (MO) e estão ilustradas no quadro 2.

Os resultados mostraram pouca variação na quantidade de carga suspensa total em todas as coletas no ponto 1 , visto que, no inverno obteve-se $12,5{\mathrm{mg} . \mathrm{L}^{-1}}^{-1}\left(5,1 \mathrm{mg}^{-\mathrm{L}^{-1}}\right.$ de MO), na estação primavera foi 9,3 mg.L-1 (6,1 de MO), na estação verão 9,2 mg.L-1 (8,7 mg.L-1 de MO), na estação outono 10,6 (6,4 mg.L-1 de MO). Esses dados mostram que próximo a área urbana a concentração de matéria orgânica aumentou nas estações chuvosas e diminuiu na estação seca.

No ponto 2 nota-se certa diferença entre a coleta realizada, no inverno com CST de 7,7 $\mathrm{mg} \cdot \mathrm{L}^{-1} \quad$ (4,9 mg. $\mathrm{L}^{-1}$ de MO) e na primavera com CST de 4,2 mg.L $\mathrm{L}^{-1} \quad\left(1,0 \mathrm{mg} \cdot \mathrm{L}^{-1}\right.$ de MO), enquanto os maiores valores foram detectados no verão com CST de 11,6 mg.L-1 $\left(9,4 \mathrm{mg} . \mathrm{L}^{-1}\right.$ de MO) e outono quando atingiu CST de 14,6 mg.L-1 (12,4 mg.L-1 de MO). Nota-se maior concentração de matéria orgânica principalmente nas estações verão e outono com redução na estação da primavera. Isso pode estar relacionado a períodos de plantio e colheita das culturas anuais.

Geografia Ensino \& Pesquisa, v. 15, n.2, p. 63-74, maio./ago. 2011

Villa, M. E. C. D. 


\begin{tabular}{|c|c|c|c|c|c|c|c|c|}
\hline Amostras & \multicolumn{2}{|c|}{ P1 } & \multicolumn{2}{|c|}{ P2 } & \multicolumn{2}{c|}{ P3 } & \multicolumn{2}{c|}{ P4 } \\
\hline mg.L-1 & CST $^{*}$ & MO* $^{*}$ & CST $^{*}$ & MO $^{*}$ & CST* $^{*}$ & MO* $^{*}$ & CST $^{*}$ & MO* $^{*}$ \\
\hline 1 $^{\text {a Coleta (Inverno) }}$ & 12,5 & 5,1 & 7,7 & 4,9 & 12 & 10,7 & 9,7 & 7,8 \\
\hline $2^{\text {a } \text { Coleta (Primavera) }}$ & 9,3 & 6,1 & 4,2 & 1 & 6,4 & 3 & 3 & 1 \\
\hline $3^{\text {a } \text { Coleta (Verão) }}$ & 9,2 & 8,7 & 11,6 & 9,4 & 18,9 & 16,3 & 10,4 & 6,5 \\
\hline $4^{\text {a } \text { Coleta (Outono) }}$ & 10,6 & 6,4 & 14,6 & 12,4 & 31,7 & 26,1 & 12,3 & 9,8 \\
\hline
\end{tabular}

Quadro 1 - Concentração de carga suspensa total (mg.L-1) na bacia do córrego Pinhalzinho II

${ }^{*}$ CST (Carga Suspensa Total); MO (Matéria Orgânica)

No ponto 3 os valores encontrados variaram bastante, no inverno obteve-se CST de 12,0 mg.L-1 (10,7 mg.L-1 de MO); na primavera CST de 6,4 mg.L-1 (3,0 mg..-1 de MO); no verão CST de 18,9 mg.L-1 (16,3 mg.L-1 de MO) e no outono CST de 31,7 mg.L-1 (26,2 mg.L-1 de MO). Esse ponto representa a bacia do ribeirão Esperança, caracterizado pela prática intensiva de cana-deaçúcar, portanto os resultados podem estar relacionados ao período de colheita que deixa o solo descoberto associado a chuvas.

No ponto 4 os valores de carga suspensa total encontrados foram no inverno $9,7 \mathrm{mg} \cdot \mathrm{L}^{-1}(7,8$ mg.L-1 MO); na primavera 3,0 mg.L-1 (1,0 mg.L-1 MO); no verão 10,4 mg.L-1 $\left(6,5 \mathrm{mg} \cdot \mathrm{L}^{-1} \mathrm{MO}\right)$ e no outono $12,3 \mathrm{mg} \cdot \mathrm{L}^{-1}$ (9,8 $\left.\mathrm{mg} \cdot \mathrm{L}^{-1} \mathrm{MO}\right)$. Os resultados mostram que no verão e outono ocorrem as maiores concentrações de CST. As maiores concentrações de MO ocorrem no outono e inverno. Isso pode estar relacionado a períodos de plantio e colheita das culturas anuais.

A análise demonstrou que a carga suspensa total (CST) na maioria dos pontos é composta principalmente pela matéria orgânica (MO). E que sua concentração sofre influência das estações do ano, em decorrência do tipo de uso do solo e da precipitação.

\section{Metais presentes na água}

Os metais representam um grupo especial de elementos químicos poluentes, em razão de não serem degradados de forma natural, possibilitando a bioacumulação e a biomagnificação na cadeia alimentar.

Esse trabalho determinou a concentração total de $\mathrm{Cu}, \mathrm{Fe}, \mathrm{Mn}, \mathrm{Ni}, \mathrm{Cr}, \mathrm{Pb}, \mathrm{Cd}, \mathrm{As}, \mathrm{Se}, \mathrm{Zn}$.

Utilizou-se como referencial a Resolução CONAMA n³57/2005, que estabelece os teores máximos ( $\mathrm{mg.L} \mathrm{L}^{-1}$ permitidos de metais em águas doces de classe II, na tentativa de se avaliar a degradação da bacia do córrego Pinhalzinho II objeto desse estudo.

A Tabela 1 mostra as concentrações dos metais $\mathrm{Cu}, \mathrm{Zn}, \mathrm{Pb}, \mathrm{Cd}, \mathrm{Mn}, \mathrm{Ni}, \mathrm{Cr}, \mathrm{As}, \mathrm{Fe}$, Se das amostras de águas coletada durante as estações: Inverno, Primavera, Verão e Outono. Conforme os resultados obtidos, verifica-se que não foram detectados concentrações significativas de $\mathrm{As}, \mathrm{Ni}, \mathrm{Cr}, \mathrm{Cu} \mathrm{Pb}, \mathrm{Cd}$ e Se.

A análise mostrou que o elemento $\mathrm{Zn}$ foi detectado em todas as coletas com teores maio.lago. 2011

Avaliação da carga suspensa total (CST) e de metais na bacia do córrego Pinhalzinho II no município de Umuarama - PR 


\begin{tabular}{ccccccccccc}
\hline \multicolumn{10}{c}{ Primeira Coleta - Inverno } \\
\hline Pontos & Cu & Zn & Pb & Cd & As & Ni & Cr & Mn & Fe & Se \\
\hline 1 & ND & 0,01 & ND & ND & ND & ND & ND & ND & 0,170 & ND \\
\hline 2 & ND & 0,002 & ND & ND & ND & ND & ND & 0,008 & 0,321 & ND \\
\hline 3 & ND & 0,010 & ND & ND & ND & ND & ND & 0,018 & 0,336 & ND \\
\hline 4 & ND & 0,017 & ND & ND & ND & ND & ND & 0,014 & 0,336 & ND \\
\hline
\end{tabular}

Primeira Coleta - Primavera

\begin{tabular}{ccccccccccc}
\hline Pontos & $\mathrm{Cu}$ & $\mathrm{Zn}$ & $\mathrm{Pb}$ & $\mathrm{Cd}$ & $\mathrm{As}$ & $\mathrm{Ni}$ & $\mathrm{Cr}$ & $\mathrm{Mn}$ & $\mathrm{Fe}$ & $\mathrm{Se}$ \\
\hline 1 & $\mathrm{ND}$ & 0,002 & $\mathrm{ND}$ & $\mathrm{ND}$ & $\mathrm{ND}$ & $\mathrm{ND}$ & $\mathrm{ND}$ & 0,107 & 1,122 & $\mathrm{ND}$ \\
\hline 2 & $\mathrm{ND}$ & $\mathrm{ND}$ & $\mathrm{ND}$ & $\mathrm{ND}$ & $\mathrm{ND}$ & $\mathrm{ND}$ & $\mathrm{ND}$ & 0,074 & 1,485 & $\mathrm{ND}$ \\
\hline 3 & $\mathrm{ND}$ & $\mathrm{ND}$ & $\mathrm{ND}$ & $\mathrm{ND}$ & $\mathrm{ND}$ & $\mathrm{ND}$ & $\mathrm{ND}$ & 0,021 & 1,496 & $\mathrm{ND}$ \\
\hline 4 & $\mathrm{ND}$ & 0,039 & $\mathrm{ND}$ & $\mathrm{ND}$ & $\mathrm{ND}$ & $\mathrm{ND}$ & $\mathrm{ND}$ & 0,158 & 2,036 & $\mathrm{ND}$ \\
\hline
\end{tabular}

Primeira Coleta - Verão

\begin{tabular}{ccccccccccc}
\hline Pontos & $\mathrm{Cu}$ & $\mathrm{Zn}$ & $\mathrm{Pb}$ & $\mathrm{Cd}$ & $\mathrm{As}$ & $\mathrm{Ni}$ & $\mathrm{Cr}$ & $\mathrm{Mn}$ & $\mathrm{Fe}$ & $\mathrm{Se}$ \\
\hline 1 & $\mathrm{ND}$ & 0.028 & $\mathrm{ND}$ & $\mathrm{ND}$ & $\mathrm{ND}$ & $\mathrm{ND}$ & $\mathrm{ND}$ & 0,029 & 0,831 & $\mathrm{ND}$ \\
\hline 2 & $\mathrm{ND}$ & 0,030 & $\mathrm{ND}$ & $\mathrm{ND}$ & $\mathrm{ND}$ & $\mathrm{ND}$ & $\mathrm{ND}$ & 0.098 & 1,652 & $\mathrm{ND}$ \\
\hline 3 & $\mathrm{ND}$ & 0,027 & $\mathrm{ND}$ & $\mathrm{ND}$ & $\mathrm{ND}$ & $\mathrm{ND}$ & $\mathrm{ND}$ & 0,162 & 2,098 & $\mathrm{ND}$ \\
\hline 4 & $\mathrm{ND}$ & 0,016 & $\mathrm{ND}$ & $\mathrm{ND}$ & $\mathrm{ND}$ & $\mathrm{ND}$ & $\mathrm{ND}$ & 0,05 & 1,934 & $\mathrm{ND}$ \\
\hline
\end{tabular}

Primeira Coleta - Outono

\begin{tabular}{ccccccccccc}
\hline Pontos & $\mathrm{Cu}$ & $\mathrm{Zn}$ & $\mathrm{Pb}$ & $\mathrm{Cd}$ & $\mathrm{As}$ & $\mathrm{Ni}$ & $\mathrm{Cr}$ & $\mathrm{Mn}$ & $\mathrm{Fe}$ & $\mathrm{Se}$ \\
\hline 1 & $\mathrm{ND}$ & 0,042 & $\mathrm{ND}$ & $\mathrm{ND}$ & $\mathrm{ND}$ & $\mathrm{ND}$ & $\mathrm{ND}$ & 0,021 & 0,245 & $\mathrm{ND}$ \\
\hline 2 & $\mathrm{ND}$ & 0,0379 & $\mathrm{ND}$ & $\mathrm{ND}$ & $\mathrm{ND}$ & $\mathrm{ND}$ & $\mathrm{ND}$ & 0,061 & 1,135 & $\mathrm{ND}$ \\
\hline 3 & $\mathrm{ND}$ & 0,037 & $\mathrm{ND}$ & $\mathrm{ND}$ & $\mathrm{ND}$ & $\mathrm{ND}$ & $\mathrm{ND}$ & 0,066 & 1,377 & $\mathrm{ND}$ \\
\hline 4 & $\mathrm{ND}$ & 0,029 & $\mathrm{ND}$ & $\mathrm{ND}$ & $\mathrm{ND}$ & $\mathrm{ND}$ & $\mathrm{ND}$ & 0,043 & 0,764 & $\mathrm{ND}$ \\
\hline$*$ & $\mathrm{Cu}$ & $\mathrm{Zn}$ & $\mathrm{Pb}$ & $\mathrm{Cd}$ & $\mathrm{As}$ & $\mathrm{Ni}$ & $\mathrm{Cr}$ & $\mathrm{Mn}$ & $\mathrm{Fe}$ & $\mathrm{Se}$ \\
\hline & 0,009 & 0,18 & 0,01 & 0,001 & 0,01 & 0,025 & 0,05 & 0,1 & 0,3 & 0,01 \\
\hline
\end{tabular}

Tabela 1- Concentração média dos metais analisados na água em mg.L-1

* Teores máximos permitidos pelo CONAMA n³57/2005

ND - valores não detectados

De acordo com os resultados obtidos, a primeira e quarta coleta o $\mathrm{Mn}$ apresentou teores abaixo de $0,1 \mathrm{mg} \cdot \mathrm{L}^{-1}$, estando portanto abaixo dos limites máximos permitidos pela Resolução CONAMA 357/2005. Na segunda coleta no ponto $1(0,107)$ e no ponto $4(0,158)$, e na terceira coleta no ponto $3(0,162)$ os valores apareceram acima dos teores máximos permitidos.

Geografia Ensino \& Pesquisa, v. 15, n.2, p. 63-74, maio.lago. 2011

Villa, M. E. C. D.

ISSN 2236- 4994 
A análise mostrou que o elemento Ferro, com exceção do ponto 1 na primeira e quarta coleta, apareceu em todos os pontos e em todas as coletas com teores acima dos permitidos de $0,3 \mathrm{mg} \cdot \mathrm{L}^{-1}$.

A análise demonstrou que os teores de ferro ( $\mathrm{Fe})$ aumentam nas estações mais chuvosas Primavera e Verão, provavelmente devido ao carreamento de solos e à ocorrência de processos de erosão das margens das drenagens favorecendo para o aumento da carga suspensa. Também pode ser originado de efluentes industriais, oriundos de indústrias metalúrgicas existentes nas proximidades dos canais.

O ferro $(\mathrm{Fe})$ é o metal potencialmente pesado que normalmente ocorre em grande quantidade nos solos fazendo com o mesmo apresente concentrações geralmente superiores aos demais. A presença desses metais pode estar relacionada com as atividades agrícolas, que são desenvolvidas na bacia. Durante a coleta de amostras foi possível constatar a utilização de corretivos e agrotóxicos nas lavouras, que aliados ao avanço da malha urbana sobre as cabeceiras produzem efluentes domésticos, industriais com o conseqüente escoamento destes para as drenagens.

\section{Conclusão}

O resultado das análises de metais em águas superficiais mostrou que as águas não apresentam contaminação por metais como: $\mathrm{Cu}, \mathrm{Ni}, \mathrm{Cr}, \mathrm{Pb}, \mathrm{Cd}, \mathrm{As}, \mathrm{Se}, \mathrm{Zn}$. Apenas o elemento Fe e Mn apresentaram teores acima dos valores máximos permitidos pela Resolução CONAMA 357 de 2005 para classe II, águas doces. Esses teores detectados podem ser provenientes do substrato geológico, pois, esses solos são classificados como latossolos argilosos e arenosos ricos em óxido de ferro e manganês, desenvolvidos a partir da alteração dos arenitos da Formação Caiuá. Esses são carreados para o rio nos momentos de maior pluviosidade, aumentando a carga suspensa total e a concentração de Fe e Mn. Observa-se nos pontos P2, P3 e P4 localizados na área rural são os apresentam maiores teores de Fe.

Os resultados da análise da carga suspensa total mostraram relativa diferença entre 0 ponto 1 localizado na área urbana e os pontos 2; 3 e 4 localizados na área rural. Observa-se que no ponto 1 há pouca variação na carga suspensa total, com representativo teores de matéria orgânica, enquanto que nos pontos localizados sob influência predominantemente rural, os teores de carga suspensa total composta principalmente por matéria orgânica variam bastante de acordo com o período do ano.

De forma geral a carga suspensa total possui significativo teor de matéria orgânica, a qual pode estar complexando os metais, impedindo que fiquem disponíveis na coluna água.

Esse estudo poderá correlacionar os processos de urbanização, industrialização e expansão populacional com a presença de metais e carga suspensa total e propor formas de controle, manejo e gestão de recursos hídricos.

Geografia Ensino \& Pesquisa, v. 15, n.2, p. 63-74, maio./ago. 2011

Avaliação da carga suspensa total (CST) e de metais na bacia do córrego Pinhalzinho II no município de Umuarama - PR

\section{Referências}

ANDRADE, C. F. F. D. Uma Introdução à Bioinorgânica. Instituto de Química e Geociências, Universidade Federal de Pelotas, Pelotas. 2003. 
BAIRD, Colin. Química ambiental. trad;Maria Angeles Lobo Recio e Luiz Carlos Marques Carrera. - 2.ed. Porto Alegre: Bookman. 2002.

CETESB, 2009. COMPANHIA DE TECNOLOGIA DE SANEAMENTO AMBIENTAL. Disponível em: http://www.cetesb.sp.gov.br/Agua/rios/variaveis. Acessado 30/04/2009.

COELHO, A. R. Dinâmica Fluvial e Qualidade da Água da Bacia de Drenagem do Ribeirão Maringá: Contribuição para o Planejamento e Gestão Ambiental. Dissertação (Mestrado em Geografia)-Universidade Estadual de Maringá, Maringá. 2007.

CONAMA. CONSELHO NACIONAL DE MEIO AMBIENTE. Resolução 357/2005. Legislação. Brasília, Disponível em: http://www.mma.gov.br/port/conama. Acesso 07/05/2009. 2005. Acesso 30/04/2009.

Forstner, U., J. Schoer and H.D. Knauth. Metal pollution in the tidal Elbe River. Sci. Total Environ. 1990.

IPARDES - Instituto Paranaense de Desenvolvimento Econômico e Social. Leituras regionais: mesorregiões geográficas paranaenses. Curitiba. 2004.

KEITH, L. Compilation of EPA'S (Environmental Agency Protection) sampling and analysis methods. 2nd Edition. New York: Lewis Publishers (CRC Press, Inc.). 1996.

KLASSEN, C.D. Metais e Antagonistas dos Metais. In: GILMAN e GOODMAN. As bases farmacológicas da terapêutica. Rio de Janeiro: Guanabara-Koogan, 1999.

LEWIS, R. J. Sax's Dangerous Properties of Industrial Materials. 9. ed. New York: Van Nostrand Reinhold, a) V. I, II and III. 1996.

MARTIN, J. M.; MEYBECK, M.; SALVADOR, F.; THOMAS, A. Pollution chimique des estuaries: état des connaissances. Centre National pour I'Explotation des Oceans. Série Report Scientifiques et Techbiques. 1976.

MAACK, R. Geografia física do estado do Paraná. $3^{\circ}$ ed. Curitiba: Imprensa Oficial. 2002.

ORFEO, O. Sedimentología del río Paraná en el área de confluencia com el río Paraguay. - Tesis Doctoral. Univ. Nacional de la Plata, Facultad de Ciencia Naturales e Museo, La Plata, Argentina, 1995.

\section{Correspondência}

Maria Estela Casle Dalla Villa - Rua: João Luiz Dias, n 459, apto. 402. Bloco 06. CEP:87023-130.

Bairro Cidade Nova - Maringá / PR.

E-mail: estelaqm1@hotmail.com

Recebido em 27 de agosto de 2010.

Revisado pelo autor em 28 de abril de 2011.

Aprovado em 26 de junho de 2011.

Geografia Ensino \& Pesquisa, v. 15, n.2, p. 63-74 maio./ago. 2011

Villa, M. E. C. D. 